\title{
PEDAGOGIAS DA MATERNIDADE NO ÂMIBITO DA POLÍTICA PRIMEIRA INFÂNCIA MELHOR/RS
}

\author{
Carin Klein ${ }^{(*)}$ \\ Dagmar Estermann Meyer ${ }^{(*)}$
}

\section{INTRODUÇÃO}

Naquela tarde, a mãe (Luciane) já estava à espera da visitadora (June) recebendo-a afetuosamente $^{1}$. A mãe sentou-se com a filha Nina (2 anos) em um acolchoado colocado sobre a terra, na área de sua casa, demonstrando ser algo já ensinado em suas visitas. A visitadora, que havia planejado atividades para as duas crianças, solicitou a Nina que retirasse alguns objetos de uma caixa e os colocasse numa sacola. Nina gostou de pegar os brinquedos, colocou-os logo na boca e até colocou-os, com a ajuda da mãe, na sacola. Igor (3 anos), irmão de Nina, não acordou. Perguntei sobre qual seria a atividade com Igor, e June respondeu que era a mesma, porém, ele teria de nomear os objetos da caixa, estimulando-o para o desenvolvimento da linguagem. Conversou-se sobre o desenvolvimento das crianças, e [...] a mãe contou que havia parado de estudar e não trabalhava fora porque precisava cuidar das crianças e que a creche próxima de sua casa era pequena e não havia vagas. Segundo ela, até tinha distribuído currículos, mas, ao finalizar a conversa, disse: "mãe que é mãe precisa cuidar dos filhos". (DC 20 abr. 2007)

Iniciamos este trabalho ${ }^{2}$ narrando uma Modalidade de Atenção Individual - de 0 a 3 anos, prevista na metodologia da política Primeira Infância Melhor (PIM) do governo do estado do Rio

\footnotetext{
${ }^{(*)}$ Doutora em Educação pela Universidade Federal do Rio Grande do Sul (UFRGS). Membro do Grupo de Estudos de Educação e Relações de Gênero (GEERGE). Professora do Programa de Pós-graduação em Educação e do Curso de Pedagogia da ULBRA/RS. Seus interesses direcionam-se para as temáticas de gênero, maternidade, infância, educação e políticas públicas de inclusão social.

${ }^{(* *)}$ Doutora em Educação pela UFRGS. Professora colaboradora convidada no Programa de Pós-graduação em Educação. É membro do Grupo de Estudos de Educação e Relações de Gênero (GEERGE) e pesquisadora com bolsa de produtividade em pesquisa do $\mathrm{CNPq}$.

${ }^{1}$ Esclarecemos que todos os nomes citados são fictícios e que as/os participantes da pesquisa assinaram o termo de consentimento livre e esclarecido.

${ }^{2}$ Este artigo constitui uma versão atualizada e ampliada do trabalho apresentado no Seminário Internacional Fazendo Gênero 10 Florianópolis, em 2012. Desdobra-se de uma tese de doutorado intitulada Biopolíticas de inclusão social e produção de maternidades e paternidades para uma 'infância melhor' produzida no âmbito do PPGEdu/UFRGS (KLEIN, 2010).
} 
Grande do Sul/Brasil ${ }^{3}$, por entendermos que ela evidencia a dimensão política que envolve os processos de educação $\mathrm{e}(\mathrm{m})$ saúde direcionados às famílias, às mulheres e às mães pobres. Essa abordagem torna-se bastante produtiva para aliar as análises de gênero, ainda pouco levadas em conta, à formulação e à implementação de políticas públicas e programas governamentais de educação e(m) saúde e/ou de inclusão social, no Brasil contemporâneo, bem como para salientar o caráter construído e fluido de categorias como família, maternidade e infância conforme preconizadas e extensivamente reiteradas no âmbito das políticas de inclusão social.

O PIM é descrito como uma política pública pioneira no Brasil, que ao completar 14 anos de existência, mantém como principal objetivo a promoção do desenvolvimento integral na primeira infância, "através de visitas domiciliares e comunitárias realizadas semanalmente a famílias em situação de risco e vulnerabilidade social, visando o fortalecimento de suas competências para educar e cuidar de suas crianças" (RIO GRANDE DO SUL, 2018). Entre os critérios de seleção das áreas atendidas pelo PIM, está o número de famílias cadastradas no Programa Bolsa Família (PBF), menor número de crianças assistidas em escolas de educação infantil, maior taxa de mortalidade infantil e maior vulnerabilidade social, estabelecendo-se, assim, pertencimento ou não.

Vale dizer que políticas públicas contemporâneas, como o PIM, assim como o atual Programa Nacional Criança Feliz ${ }^{4}$, se revestem de uma racionalidade neoliberal ao investir numa parcela da população pobre no sentido de dirigir e conformar os processos de gestão da vida, ao mesmo tempo em que efetivam o enxugamento e a redução do Estado. Isso inclui a produção de uma retórica em torno da redução das vulnerabilidades sociais e da inclusão social de determinados grupos populacionais, fundamentalmente, os pobres, a fim de garantir, por exemplo, o desenvolvimento infantil saudável, expresso através de políticas públicas voltadas à primeira infância. Nesse sentido, interessa-nos indicar a estreita articulação que se faz entre determinadas formas de exercício da maternidade, vulnerabilidade social e políticas públicas, pois é nessa conexão que as mulheres são ensinadas e posicionadas como agentes centrais de operacionalização das políticas que as chamam a responder e a se responsabilizar pelas ações propostas.

\footnotetext{
${ }^{3}$ No dia 7 de abril de 2003, Dia Mundial da Saúde, o PIM foi lançado pelo então governador do estado do Rio Grande do Sul, Germano Rigotto. Embasado na experiência teórico-metodológica do programa cubano Educa Tu Hijo, tornouse política pública em 3 de julho de 2006, com a lei estadual n. 12.544/2006.

${ }^{4}$ O Programa Criança Feliz foi criado por meio do Ministério do Desenvolvimento Social, através do decreto 8.869/2016, do dia 05/10/2016. As propostas do Programa Criança Feliz tomam como base os conhecimentos e a metodologia, instituídas no PIM/RS. Vale lembrar, que o atual ministro do Desenvolvimento Social, foi o então Secretário de Saúde do Rio Grande do Sul, nos governos Germano Rigotto (2003-2007) e Ieda Cruzius (2007-2011), período em que o PIM foi implantado como Programa e implementado como Política Pública neste estado.
} 
A pesquisa realizada inscreve-se nos campos dos estudos de gênero e dos estudos foucaultianos, e o material empírico, examinado na perspectiva da análise de discurso, foi produzido em um trabalho de campo de caráter etnográfico, realizado no município de Canoas/RS ${ }^{5}$. Analisamos o PIM enquanto uma política governamental de inclusão social e/ou educação em saúde, a fim de entendermos como ela atua na construção de estratégias educativas que procuram associar a educação das famílias, por meio do exercício e da delimitação de funções maternas, com a promoção de ações sistemáticas em torno do desenvolvimento integral das crianças de zero a seis anos.

Assumindo o pressuposto de que a linguagem é produtora das práticas sociais, tornou-se importante explorar neste trabalho: a) a metodologia PIM, anunciada em seus documentos, bem como através da materialidade expressa por meio das falas, brincadeiras, conselhos, ensinamentos de educação $\mathrm{e}(\mathrm{m})$ saúde, das "modalidades de atenção" protagonizadas pelo/as técnico/as e visitadoras e dirigidas às mulheres e crianças que buscam/ram conformar; b) o que as famílias, sobretudo através das mulheres-mães, precisam apreender a fim de melhor cuidar das crianças e ensiná-las ${ }^{6}$; c) as aproximações formadas/produzidas entre a prática do cuidado materno (que envolveu/envolve contracepção, reprodução, amamentação, alimentação, higiene, educação e cuidado infantil, estimulação e desenvolvimento infantil) e as propostas de educação e(m) saúde (da mulher/família e) para a produção de uma “infância melhor".

A concretização da política ocorria/ocorre principalmente através das visitas domiciliares a fim de privilegiar o acompanhamento e a intervenção direta às famílias. O trabalho acontecia, semanalmente, através das Modalidades de Atenção Individual (nos domicílios, com crianças de zero a três anos) e Grupal (geralmente em locais cedidos pela comunidade, como escolas, igrejas ou associações, com crianças de três a seis anos). As visitadoras (tal como June) - elos entre os técnicos e as famílias pobres - necessitavam cadastrar, planejar, orientar, desenvolver atividades domiciliares e grupais, elaborar materiais pedagógicos, acompanhar e controlar a qualidade das ações educativas que as famílias devem realizar, promovendo a estimulação adequada e visando ao

\footnotetext{
${ }^{5} \mathrm{O}$ trabalho de campo de caráter etnográfico foi realizado no município de Canoas/RS e ocorreu ao longo de onze meses - de março de 2007 a janeiro de 2008 - através da observação e do registro do trabalho desenvolvido pelas visitadoras e pelos/as técnicos/as, com as mulheres-mães e, ainda, da seleção e a análise dos documentos oficiais referentes ao PIM. Durante este período, realizou-se o acompanhamento e o registro em um diário de campo de 40 atividades, entrevistas com seis mães, sete visitadoras e com os/as três técnicos/as.

${ }^{6}$ Para visualizar as orientações dirigidas as famílias consultar a edição atualizada do Guia da Família (RIO GRANDE DO SUL, 2016) ou <http://www.pim.saude.rs.gov.br/v2/guia-da-familia-acervo/>.
} 
desenvolvimento integral das crianças de zero a seis anos, desde a gestação (RIO GRANDE DO SUL, 2007) ${ }^{7}$.

Torna-se importante destacar que o trabalho etnográfico não visa à totalidade das coisas, considera sim as condições de produção de determinadas regras, crenças, conhecimentos, distâncias, aproximações. Um estudo que, conforme Clifford Geertz (2008, p. 20), consiste na produção de "uma leitura", nesse caso, sobre algumas atividades realizadas com as famílias atendidas pelo PIM, a fim de delinear a polifonia de vozes, perspectivas, provocações, entendimentos e incompletudes do contexto investigado; permitindo-nos mapear alguns dos conhecimentos, em sua articulação com o poder, que são constitutivos do PIM e que marcam e definem lugares específicos a mulheres-mães (mas também as visitadoras e técnicos/as), conhecimentos que puderam ser apreendidos e revisitados através das muitas histórias e sentimentos que, talvez por meio do olhar, da escuta, da escrita e da reflexão, possam ser, parcialmente, traduzidos e refeitos (CALDEIRA, 1988; FONSECA, 1999).

A produção de espaços educativos que incluíam as "modalidades de atenção" atuavam no sentido de permitir a implementação de processos de interação entre visitadoras e mães para transmitir conhecimentos, informar valores, expor noções, apresentar e desenvolver as chamadas "competências familiares", a fim de investir em valores tomados, muitas vezes, como "naturais" para disciplinar, ordenar e gerir modos de ser e viver. Claudia Fonseca (1999) nos diz que precisamos refinar as análises para não escorregarmos em noções do senso comum capazes de guiar nossa compreensão sobre algo, tomando, por exemplo, determinadas relações e dinâmicas familiares como "desestruturadas", "desorganizadas" ou "desfavoráveis". A fim de dar conta das análises e poder apreender significados particulares de alguns indivíduos ou dos grupos com os quais interagimos, tornou-se necessário desarranjar alguns processos de naturalização muito persistentes em nossa cultura, como o da mãe-mulher cuidadora e abnegada e o do homem-pai desresponsabilizado das atribuições que envolvem o cuidado e a educação dos/as filhos/as, representações veiculadas na grande maioria das cartilhas e materiais educativos divulgados em campanhas, programas e políticas públicas de educação e(m) saúde.

Nesse sentido, a maternidade que a visitadora buscava ensinar a mãe, ao realizar a atividade domiciliar, tal como descrevemos no início deste trabalho, não existia a priori - precisava ser constantemente reinventada, enunciada, repetida e ensinada. Tanto as visitas domiciliares, como as

\footnotetext{
${ }^{7}$ A escolha das visitadoras dessa pesquisa ocorreu por meio de alguns critérios, como: ser moradora da comunidade, possuir primeiro grau completo, alguma experiência de voluntariado e demonstrar proximidade ou desejo em trabalhar com crianças.
} 
reuniões comunitárias que envolviam os encontros com gestantes e puérperas davam lugar à conformação dos sujeitos, ao esquadrinhamento dos corpos e dos espaços, da produção do que contava como "natural" ou não, fazendo com que Luciane, por exemplo, seguisse o enunciado de que "mãe que é mãe precisa cuidar dos filhos". Consequentemente, "não trabalhar fora" indicava ficar em casa para brincar, cuidar das crianças, ficar à espera da visitadora e receber seus ensinamentos, e isso era significado como fazer algo acertado para que uma determinada forma de ser mãe se concretizasse, deixando de fora, nesse movimento, os jogos de saber e poder que a instituem e buscam torná-la homogênea. É com o propósito de visibilizar os argumentos que delineavam o que nomeamos como pedagogização da maternidade que exploramos a seguir, como ocorria a Modalidade Grupal de Atenção à Gestante, proposta na metodologia PIM, e em como as orientações ali delineadas eram atravessadas por pressupostos de gênero, em uma educação voltada às mulheres e à maternidade.

\section{REUNIÕES COMUNITÁRIAS: O CHÁ DOS BEBÊS}

O Chá dos Bebês, denominação dada a essa atividade pelo Grupo Técnico Municipal (GTM) fazia parte da Modalidade Grupal de Atenção à Gestante, proposta no Guia de Orientação para GTM, Monitor e Visitador (RIO GRANDE DO SUL, 2007). Eram reuniões, coordenadas pelo Grupo Técnico Municipal (GTM), que aconteciam semanalmente, não exatamente com a finalidade prescrita nos Guias, uma vez que os encontros passaram a se constituir como um meio de dar continuidade ao trabalho do PIM quando não se contava mais com as idas das visitadoras às residências, tampouco com a realização das modalidades de atenção individual e grupal que elas desenvolviam $^{8}$. Em um primeiro momento, as atividades foram direcionadas especificamente às gestantes e, posteriormente, à comunidade em geral. O Chá dos Bebês ocorria na Associação Getúlio Vargas, no Bairro Mathias Velho, em Canoas, pois, de acordo com o GTM, havia naquela comunidade, um número maior de mulheres gestantes consideradas em situação de vulnerabilidade social.

Nas rodas de conversa que eram formadas a cada novo encontro, observávamos como os/as técnicos/as mantinham como prática constante devolver as perguntas para as mulheres, a fim de ouvir delas experiências, expectativas e entendimentos e, assim, legitimar o que consideravam

\footnotetext{
${ }^{8}$ Em março de 2007, período em que iniciou o trabalho de campo, havia sete visitadoras e uma monitora contratada. Pela ausência das contratações, a previsibilidade da política se rompia, e a equipe de técnicos/as precisava lançar mão de modalidades de atendimento que não estavam delineadas nas orientações e na metodologia. Pelo que acompanhei no município, a não contratação estava diretamente associada a tensões político-partidárias. Naquele momento, o PIM Canoas deixava de cumprir as chamadas Modalidades de Atenção (KLEIN, 2010).
} 
apropriado e desmistificar as noções do senso comum, que tomavam como "crendices populares". Compreendíamos que buscavam construir sua atuação com o propósito de auxiliá-las e orientá-las em suas atividades diárias e com o cuidado e a estimulação de seus bebês. Em um desses encontros, o pediatra que também coordenava o PIM falava sobre a gestação como uma fase de acolhimento do bebê e que fazia parte desse acolhimento a preparação das roupas, da sacola que deveria ser levada ao hospital, do cuidado com a higiene corporal. Em um dos registros das atividades do PIM, foi salientada a fala de uma técnica que explicava sobre a importância da palavra resiliência, que, no campo da psicologia, segundo ela, se referia à capacidade de vencer ou superar as dificuldades. Disse ela que tal capacidade era "própria da mulher e da mãe" e que "não é por acaso que é a mulher que engravida" (DC, 20 abr. 2007).

A forma como técnicos/as, visitadoras, mulheres e homens significam e conduzem suas práticas está relacionada com a forma como são pensados e ensinados a dirigir suas vidas. Esses processos não são lineares, tampouco homogêneos, pois estão diretamente vinculados a sistemas embutidos na linguagem que incidem sobre a formulação de leis, pareceres, imperativos, recomendações. Cabia-nos refletir sobre o conceito de resiliência referido pela técnica para atrelar ao feminino um entendimento naturalizado de maternidade. Compreendemos que os ensinamentos organizados para promover as ações educativas que visavam ao cuidado infantil também se pautavam, naquele momento, por um raciocínio generificado, acionado pela política para atuar na condução de quem precisava ser mais bem governado. Afinal, é importante destacar que esse grupo de mulheres só "precisava ser ensinado" no âmbito do PIM porque houve "falhas" em outras estratégias de governo exercidas em outros momentos sobre esses indivíduos (PARAISO, 2011).

Assim, a discursividade em torno do desenvolvimento infantil e a recorrente associação deste com o exercício de certa forma de investir na maternidade passavam a ancorar-se numa pretensa neutralidade, que ganhava força ao colocar a ciência e a biologia como fundamentos das explicações educativas, ao mesmo tempo em que o cuidado com a criança seguia sendo representado como uma competência do feminino, pois envolveria sentimentos amorosos e tarefas "próprias da mulher e da mãe" - como disse a técnica, acrescentando ainda "não é por acaso que é a mulher que engravida".

Nessa direção, o trabalho etnográfico contribui para a desconstrução do "mito do amor materno" (BADINTER, 1985), pois, por um lado, dá visibilidade a uma rede de discursos que descrevem e constituem o dom inato de quem deve cuidar e, por outro, permite dar visibilidade a ausência dos homens como cuidadores, assim expressando não um simples esquecimento, mas a 
própria condição em que se estruturam as relações sociais e os conhecimentos acionados em torno delas, o que inclui a educação e a saúde da família e da infância.

Ao se falar sobre o processo de generificação de conceitos como resiliência ou mesmo cuidado, importa compreender o que esse processo produz, ou seja, de que forma significa e reforça determinadas representações de maternidade e gênero enquanto exclui e/ou minimiza, desvalorizando, a participação e a responsabilização dos homens nessa esfera e que efeitos isso produz sobre as formas de viver de homens e mulheres, alvos de políticas públicas como o PIM. Se o gênero é constituído e constituinte de relações sociais, torna-se importante pensar que determinadas representações de maternidade e paternidade são acionadas em um determinado contexto cultural, atravessando e constituindo formas científicas, dentre outras, de conhecer e de tornar esses conhecimentos possíveis (MEYER, 2006; 2011).

Ao término de cada encontro, que mesclava momentos lúdicos e de informação, as mulheres permaneciam ali, levantavam-se aos poucos, puxavam conversa com os/as técnicos/as, esclareciam algumas dúvidas e, em alguns momentos, pareciam querer resgatar aspectos não vivenciados na sua própria infância. Queremos dizer com isso que, para muitas mulheres, aquele espaço pedagógico significava algo diferente da socialização e do reconhecimento acionado através da maternidade. Para algumas mulheres, ele se constituía numa vivência muito particular:

Vó Maria (60 anos) é uma das integrantes mais assíduas do grupo e leva Edna (5 anos) para as atividades. Ela é muito afetiva com os/as técnicos e mostra-se sempre alegre nas brincadeiras e atividades propostas, se envolve e se diverte. Ela é que realiza as atividades propostas para que ela faça com a neta - parece querer resgatar o que não viveu. Quando há o fechamento do encontro, ela diz que adora as atividades porque, na sua infância, não pode brincar, nem estudar, tampouco quando foi mãe, e que agora faz isso ali. (DC 23 jan. 2008).

O excerto sinaliza aspectos de uma pessoa que era vista e naturalizada na posição de sujeito cuidadora, assim como outras mulheres que participaram daquelas atividades, mas que não conseguia reconhecer-se nesse lugar e cumprir os objetivos dos encontros, no sentido de realizar as atividades ali propostas com a neta, ou seja, ensiná-la ou simplesmente auxiliá-la a pintar, cortar, colar, cantar ou contar histórias. Os ensinamentos do PIM não cumpriam a função de interpelá-la na posição de sujeito mãe, avó ou professora, pois naquele espaço era ela quem queria aprender e experienciar o que era oferecido. Se naquele grupo ser mulher funcionava como um requisito para ser uma cuidadora competente e, por isso, dotada de um chamado instinto maternal, vó Maria 
resistia e rompia com essa linearidade, não se deixava capturar pelos controles discursivos da politica, fazendo-nos refletir sobre as "rasuras" que eram operadas nos objetivos e na operacionalização do PIM. Além disso, a experiência dessa mulher-avó também rachava a tentativa de homogeneizar sentidos em torno de representações maternas amorosas, atenciosas e estimuladoras, como preconizava o PIM, pois indicava o quanto a tarefa de pedagogizar a maternidade está enredada na cultura e responde a necessidades de cada período histórico. Ficava implícita a teia de poder que atribuía à maternidade uma suposta "natureza" e fixidez, dando lugar à provisoriedade, fluidez, ambivalência e constante reconstrução.

Como já indicamos, o foco dos encontros era intercalado entre atividades mais lúdicas, voltadas para o trabalho com as mulheres e crianças, e assuntos em torno da gestação, parto, amamentação, puerpério, estimulação, etc. Para descrever melhor os assuntos relacionados à maternidade, fazemos uso de um relato mais extenso, um encontro em que as mulheres deveriam pegar um objeto da "caixa da gestante" e formular uma pergunta referente à gestação, ao parto ou ao bebê que iria nascer. A atividade, coordenada por uma das técnicas, contava ainda com a participação do coordenador do PIM, visitadoras e de estagiárias da área de psicopedagogia:

A técnica solicitou às gestantes que retirassem um objeto da caixa e pensassem numa pergunta que o relacionasse à gestação ou ao parto [...]. Em geral, as gestantes se colocavam de forma muito tímida. Luísa (que havia sido visitadora e agora fazia parte do grupo como gestante) pegou um objeto, uma fralda, e foi logo dizendo que era muito dinheiro colocado fora, mas que era algo muito necessário. Então, perguntou: "Até quando a criança deve usar fraldas?". Uma das estagiárias em psicopedagogia respondeu que era até um ano e meio, aproximadamente, e que isso dependeria da mãe, do estímulo que ela desse para retirar as fraldas. Disse que nessa fase a criança via o cocô como parte dela, por isso a mãe poderia incentivar o bebê a dar tchau ao cocô, para a criança aprender e ir se desprendendo dele. Continuou sua resposta dizendo que a mãe deveria observar a idade e o horário em que o bebê fazia suas necessidades, para começar a colocar a criança no penico e então, gradativamente, tirar as fraldas. Finalizou dizendo que, se o cocô escapasse no começo, era normal e que nessas situações não se deveria punir a criança, e sim colocar outra roupa. Outra mãe pegou um bico e disse que seus dois filhos não chuparam. Acreditava que o bico estragaria os dentes e perguntou se ele era mesmo necessário. A técnica pergunta às mães se elas consideram o bico importante, e uma gestante sorriu e respondeu que sim: "Quando as crianças choram, as mães que não têm paciência tacam o bico na boca dos filhos". Também foi dito que, no 
próprio hospital, as enfermeiras exigiam das mães um bico para a criança parar de chorar. Discordando da opinião das enfermeiras (do hospital), o coordenador respondeu que não havia necessidade do bico e que o melhor era não oferecê-lo, principalmente, com doce ou mel. Outra mulher pegou um urso de pelúcia, disse que ele era fofinho e pensou na necessidade de dar carinho e afeto. Outra mulher pegou a boneca e disse que a criança tinha o direito de brincar. Outra pegou uma calça de bebê e falou que as roupas eram uma parte importante da preparação para receber o bebê e que, vendo aquela roupinha, ficava imaginando como o seu filho ficaria nela. Outra tirou um bebê de brinquedo pelado e perguntou se a roupa interferia na temperatura da criança. A resposta foi afirmativa. Segundo o coordenador, o corpo tem a pele e, logo abaixo dela, uma camada de gordura que protege nosso organismo do frio, sendo importante perceber a temperatura do bebê e observar alguns sinais: se ele está suando, tem febre, resmunga. Por fim, outra mulher pegou uma mamadeira e perguntou até quando deveria fazer uso dela. $\mathrm{O}$ coordenador respondeu que o peito deveria estar sempre em primeiro lugar, que era através do leite materno que a mãe alimentaria o bebê corretamente e que o leite mudava de acordo com a necessidade da criança. Disse também que a mamadeira, além de não conseguir ajustar-se às necessidades do desenvolvimento da criança, ainda poderia acumular germes. Então, ele olhou para uma das pesquisadora e disse que não havia verdades absolutas. Falou que, quando ele era criança, o incentivo era voltado para a amamentação industrial, mas que agora se recomendava e se acreditava que nada era melhor que o leite materno. A ênfase do trabalho daquela equipe estava em viabilizar um determinado tipo de cuidado com as crianças, mesmo quando o contexto não fosse "ideal". O encontro transcorreu a partir de dúvidas comuns: sobre quando introduzir ou retirar o bico, fralda, mamadeira, amamentação; sobre higiene, doenças e os primeiros cuidados com o bebê, como banho e limpeza dos órgãos genitais. Também se falou muito na estimulação dos bebês e das crianças maiores. No encerramento, cada gestante recebeu uma fralda, embrulhada como um presente. (DC, 20 abr. 2007)

Sabe-se que falar em concepção, gravidez, cuidado, desenvolvimento humano, saúde ou doença significa, em nossa cultura, fazer uso de conhecimentos específicos que são, sobretudo, das Ciências Biológicas, pautados por princípios de universalidade que permitem mapear e explicar noções comuns a indivíduos de diferentes tempos e culturas. Contudo, pode-se pensar que conhecimentos referentes à gravidez e à maternidade estão inseridos nas maneiras como os indivíduos se organizam, se mantêm e concebem o cuidado, o corpo e a saúde, produzindo nessa relação regras e comportamentos próprios (VICTORA et al. 2000). 
No entanto, a discussão que procuramos fazer nesse momento é a de que o que nomeamos como natureza ou como cultura são fenômenos sociais, circunstanciais e elaborados a partir de parâmetros de cada sociedade. A gestação e a amamentação, por exemplo, são fenômenos privilegiados para pensarmos nos conhecimentos dirigidos às mulheres-mães, bem como nos sentidos que essas práticas revelam em torno do que é acionado ora pela biologia, ora pela cultura. São sentidos que oscilam e se fundem, dependendo dos interesses, das circunstâncias e do lugar. São sentidos que privilegiam ora a criança, ora a mulher como foco das intervenções dos profissionais e das políticas de educação e(m) saúde. São, ainda, sentidos produzidos em meio a condicionantes sociais, econômicos, políticos e culturais (GOMES, 1999; ALMEIDA, 1999).

Shore e Wright (1997) entendem que os sistemas políticos operam na esfera do discurso. Como fenômenos da cultura, atuam na produção de significados e configuram formas particulares de constituir subjetividades e estruturas de poder. Eles se difundem e impactam mais o social quando se tornam capazes de mobilizar símbolos e metáforas de poder (e de gênero), por exemplo, em ações como: reuniões (conforme narramos acima), Escolha do Bebê mais Saudável ${ }^{9}$, Bebê Amigo do Peito, Gestante Nota $10^{10}$, Bebê Cidadão ${ }^{11}$. Também podem ser difundidos através do uso de recursos como o Cartão do Programa Bolsa Família (PBF), a Caderneta de Saúde do/a Adolescente, a Caderneta da Gestante e a Caderneta de Saúde da Criança. Pode-se pensar na produção de um extenso currículo, que se propõe a veicular propostas educativas que estão implicadas em representações de mãe apropriada capazes de influenciar as pessoas na direção de construírem (e avaliarem) a si mesmas, suas condutas e suas relações sociais como se essa construção de si fosse expressão da sua liberdade. É também no bojo da constituição de conceitos como "família" e "sociedade" (e maternidade) que se concentra a importância de problematizar as instituições políticas e os mecanismos de poder como possibilidade de projetar outras configurações para o social (SHORE; WRIGHT, 1997).

Nessa direção, a retórica do "amor materno" também pode ser pensada como metáfora de poder que, ao longo da história, tem convocado diferentes mulheres, de todas as nações e raças, a se reconhecerem como mães. Podemos pensar que um dos efeitos de poder dessa metáfora pode residir

\footnotetext{
${ }^{9}$ Durante a realização do trabalho de campo, a Escolha do Bebê mais Saudável foi uma ação corrente em Canoas. O concurso Bebê Amigo do Peito foi idealizado para incentivar a amamentação, podendo participar bebês entre 0 e 6 meses alimentados exclusivamente com leite materno.

${ }^{10}$ A ação Gestante Nota 10 objetivava uma gravidez saudável, através de consultas médicas regulares.

11 Anualmente, ocorre na cidade de Canela a Semana do Bebê. O primeiro bebê a nascer durante a jornada de 2010 tornou-se o bebê-prefeito, que, enquanto "cidadão", recebeu as chaves da cidade. Disponível em: <www. semanadobebe.com.br>.
} 
em tornar todas as mulheres mães e, como mães, torná-las uma só. Nesse movimento, todas as diferenças são apagadas, reduzem-se a multiplicidade, a especificidade, o conflito e a diferença, e a maternidade passa a ser invocada como uma identidade coletiva (SCOTT, 2002).

O poder dessa metáfora pode ser pensado ainda por meio de estratégias discursivas capazes de legitimar formas concretas de organização e significação das relações sociais em determinados lugares, épocas e contextos sociais. A força de enunciados (FOUCAULT, 2000), como "mãe só tem uma", "é instinto materno", "mãe que é mãe precisa cuidar dos filhos" e "não é por acaso que é a mulher que engravida", podem servir como referência para convocar alguns sujeitos a assumirem certas posições, comportamentos e/ou atitudes tomadas como naturais. Assim, alguns modos de ser e agir podem ser explicados como algo que já está determinado no interior dos corpos (nos genes) ou remetidos para explicações de cunho exterior, seja da condição humana, da cultura ou de desígnios divinos.

As modalidades enunciativas como formas particulares de atuação do discurso podem ser regras, descrições, formulação de hipóteses, formas de ensinar que posicionam os sujeitos como parte de determinados discursos. A formulação da análise do discurso refere-se ao exame da constituição do social, uma vez que "[...] o discurso constitui os objetos do conhecimento, os sujeitos e as formas sociais do 'eu', as relações sociais e as estruturas conceituais" (FAIRCLOUGH, 2001, p. 64). Situadas social e historicamente, as formações discursivas atuam através de um conjunto particular de enunciados que lhe pertencem. Dessa forma, o sujeito mãe pode se constituir a partir de modalidades enunciativas e pelas posições de sujeito (re)asseguradas pelas normas vigentes dos discursos médico, feminista, da mídia, da neurociência, das políticas públicas; ou seja, trata-se, aqui, de uma forma de análise que confere um lugar central para o discurso na constituição da maternidade (KLEIN, 2018).

Joan Scott (1995) argumenta que é no âmbito da política que noções relativas a gênero têm sido empregadas para legitimar e reafirmar comportamentos e práticas a fim de posicionar continuamente homens e mulheres em lugares sociais distintos. Nesse sentido, tanto o gênero quanto a política se inter-relacionam e passam a operar na construção de relações diferenciais de poder. Ancorada nessa autora, podemos analisar como os símbolos - que neste contexto incluem caixa da gestante, fralda, boneca, urso de pelúcia, roupa, sacola, mamadeira, bico - passaram a funcionar como elementos simbólicos, constitutivos e capazes de acionar representações de gênero, importando pensar como e em que contexto eles eram/são invocados por meio das ações pedagógicas destinadas às mulheres. 
Desse modo, os objetos circulavam por aquele espaço em meio a uma socialização para a maternidade e eram evocados e relacionados com funções que as mulheres necessitavam aprender e desempenhar: "retirar as fraldas vai depender da mãe, do estímulo que ela der" ou "quando as crianças choram, as mães que não têm paciência tacam o bico na boca dos filhos". Demonstrava-se que as mulheres deveriam compartilhar um mesmo conjunto de códigos, reiteradamente associados a símbolos, experiências, conhecimentos, profissionais e instituições na direção de confirmá-las e reconhecê-las como principais protagonistas daquelas ações educativas.

Através da socialização que ocorria naqueles encontros, compreendíamos que as mulheres se sentiam valorizadas e prestigiadas na função que lhes era atribuída - a materna -, buscando incorporar muitos dos conhecimentos ali desenvolvidos. Quando seus bebês nasciam, elas os levavam para os encontros como se fossem para uma festa, parecendo confirmar sua apropriação das "lições" oferecidas, além de compreender que aquele era também um código que representava sua dedicação e interesse para com as crianças, servindo, portanto, como um meio de julgamento e de avaliação de suas práticas. Com isso, não pretendemos dizer que as mulheres se apropriavam de forma linear e consensual de uma pedagogização para a maternidade que ocorria por meio das proposições difundidas naqueles encontros. Eles eram uma forma, mas não a única, de disputar sentidos para o que estava em jogo - definições para "corpo", "maternidade", "atenção", "cuidado", "negligência" e "educação", só para citar algumas (KLEIN, 2015; KLEIN, MEYER e BORGES, 2013; MEYER, 2009).

As estratégias educativas preconizadas e desenvolvidas no âmbito do PIM produziam um "currículo" específico, voltado para a produção de uma determinada forma de exercer a maternidade e realizar as ações voltadas para o desenvolvimento infantil, posicionando as mulheres pobres no centro de políticas de gestão da vida. Dessa maneira, a formulação de inúmeros programas e políticas públicas de inclusão social, campanhas, manuais, cartilhas, guias, cadernetas, folders, revistas, jornais, anúncios e outras formas de comunicação, vêm incorporando e difundindo prescrições e ensinamentos que deverão constituir determinadas formas de viver a maternidade e, posicionar a mulher como um sujeito mãe capaz de agir na organização doméstica e familiar, na promoção de educação e saúde como principal agente para alcançar as metas em torno da diminuição da mortalidade infantil e da ampliação da inclusão social, por exemplo, necessitando ser problematizadas. 


\section{PARA CONCLUIR...}

Indagar sobre a forma como teorias, leis, símbolos, ações educativas, instituições e políticas governamentais incorporam e atualizam pressupostos de gênero significa apreender as disputas políticas e de poder que reposicionam corpos e sujeitos e interferem na produção dos significados para o feminino e a maternidade. A partir dessa premissa, buscamos refletir sobre os discursos e as práticas sociais que sustentam enunciados como o que diz que "mãe que é mãe precisa cuidar dos filhos" e que contribuem, tanto para reforçar a invisibilidade paterna na arena da educação e do cuidado, como para dar visibilidade aos mecanismos culturais que envolvem as formas de subjetivação e diferenciação entre homens e mulheres, acabando por reforçar a desigualdade de gênero.

A escolha metodológica de acompanhar e vivenciar as atividades desenvolvidas por técnicos/as e visitadoras com as mulheres-mães permitiu-nos reunir elementos e informações na direção de compreender e problematizar aspectos relacionados a formas de negociar, socializar-se, ensinar, aprender e resistir daquelas mulheres e de suas famílias. Nesse sentido, apreendemos limitações muito concretas dos ensinamentos propostos pelo PIM, o que indica a necessidade de se refletir sobre noções de saúde, cuidado, negligência, estímulo, aprendizagem, dentre outras que nos são apresentadas como "dadas", colocando-as sob rasura e/ou ampliando-as.

Pode-se refletir ainda, que é por meio de justificativas e proposições instituídas através do PIM que o Estado vincula vulnerabilidade com pobreza (e falta de conhecimento), assim como maternidade com cuidado para, a partir disso, acionar e responsabilizar a família, através da mulher e do exercício da maternidade, para a realização da chamada "inclusão social”. Porém, torna-se importante destacar o movimento de individualização da vulnerabilidade, pois, ao mesmo tempo em que o indivíduo precisa ocupar-se em fazer consigo e com as crianças tarefas relativas à educação e à saúde, deixa-se de fora a reflexão sobre os componentes sociais e programáticos da vulnerabilidade, a carência de serviços básicos e/ou a escassez e inoperância destes.

Convocar as mulheres pobres como co-responsáveis do Estado pela produção de educação e saúde possivelmente traz algumas positividades para as crianças e famílias alvo das políticas, mas não dá conta de "excluí-las" da pobreza e da vulnerabilidade social, uma vez que as próprias políticas passam a incorporar pressupostos que atuam no sentido de excluir, quais sejam: o enxugamento e a redução do Estado; a responsabilização dos indivíduos (sobretudo, das mulheres) pela sua saúde e bem-estar e pelo provimento dos meios necessários para alcançá-los; políticas embasadas em conhecimentos generalizantes e universais a fim de atuar no cumprimento de imperativos que excluem muitos indivíduos de suas proposições; a vulnerabilidade programática 
que parece inerente às políticas de inclusão; enfim, fatores importantes que operam e contribuem para a ampliação da desigualdade (e da exclusão) que a política, inicialmente, se propõe a eliminar.

Por fim, gostaríamos de evidenciar o quanto a construção da pesquisa etnográfica, assim como a experiência da participação no campo estão condicionadas às posições de sujeito que assumimos. A escrita parte de um lugar particular que pretende desconstruir e problematizar alguns significados atrelados às relações de gênero; porém, ao considerar que a centralidade da linguagem é afirmada nessa perspectiva, podemos narrar e ser narradas/os sem escapar das formas de produção de saber, controle e regulação que nos propomos a discutir e analisar. É preciso dizer que não tivemos a intenção de pensar o Estado e/ou as políticas governamentais como instrumentos de um poder macro, dominante ou de exploração, tampouco apresentar um modelo que pudesse ser tomado como o mais correto. Partimos da compreensão de que ocupamos e transitamos por diferentes lugares, como, por exemplo, mulheres, mães, não mães, estudantes, professoras universitárias, funcionárias públicas, ou seja, posições que interagem em um campo de poder e no desenvolvimento de nossas investigações. Desse modo, o Estado e as políticas públicas que analisamos não são entidades distantes das relações que estabelecemos e às quais pertencemos; pelo contrário, somos parte dessas redes de relações, cotidiana e provisoriamente, por serem produções do nosso tempo e lugar histórico. Com isso, indicamos que a intencionalidade das análises que realizamos constitui um exercício para buscar compreender como nos tornamos sujeitos de determinados tipos e que discursos e mecanismos de poder atuaram/atuam nessas produções. 


\section{REFERÊNCIAS}

ALMEIDA, João Aprígio Guerra de. Amamentação: um híbrido natureza-cultura. Rio de Janeiro: Editora Fiocruz, 1999.

BADINTER, Elizabeth. Um amor conquistado: o mito do amor materno. São Paulo: Círculo do Livro, 1985.

BRASÍLIA, Ministério da Saúde. Secretária de Atenção à Saúde. Departamento de Ações Programáticas Estratégicas. Caderneta de Saúde da Criança: passaporte de cidadania. 10. edição, 2015. (Documento em forma de Guia). 96p.

CALDEIRA, Teresa. A presença do autor e a pós-modernidade em antropologia. In: Novos Estudos, n. 21, p. 133-157, 1988.

FAIRCLOUGH, Norman. Discurso e mudança social. Brasília: UnB, 2001.

FONSECA, Claudia. Quando cada caso não é um caso: Pesquisa etnográfica e educação. Revista Brasileira de Educação, n. 10, p. 58-78, 1999.

FOUCAULT, Michel. A arqueologia do saber. 6. ed. Rio de Janeiro: Forense Universitária, 2000.

GEERTZ, Clifford. A interpretação das culturas. Rio de Janeiro: Guanabara Koogan, 2008.

GOMES, Romeu. Prefácio. In: ALMEIDA, João Aprigio G. Amamentação: um híbrido natureza-cultura. Rio de Janeiro: Editora Fiocruz, 1999.

KLEIN, Carin. Biopolíticas de inclusão social e produção de maternidades e paternidades para uma infância melhor. Tese (Doutorado em Educação) - Programa de Pós-Graduação em Educação. Universidade Federal do Rio Grande do Sul, Porto Alegre, 2010.

KLEIN, Carin. Discursos que concorrem para a produção de infância e maternidade em políticas de inclusão social. Textura, Canoas, v. 20, n. 43, p. 53-78, maio/ago. 2018.

; MEYER, Dagmar Estermann. Mulheres-visitadoras, mulheres-voluntárias, mulheres da comunidade: o conhecimento como estratégia de diferenciação de sujeitos de gênero. Cadernos Pagu, v.1, p. 427-455, 2015.

; MEYER, Dagmar Estermann e BORGES, Zulmira. Políticas de inclusão social no Brasil contemporâneo e educação da maternidade. Cadernos de Pesquisa, v. 43, n. 150, p. 906-923, 2013.

MEYER, Dagmar Estermann. A politização contemporânea da maternidade: construindo um argumento. Gênero: Núcleo Transdisciplinar de Estudos de Gênero - NUTEG, v. 6, n. 1, p. 81-104, 2006.

Corpo, Saúde e Gênero. Fragmentos de histórias sobre corpos e vidas maternas. In: TORNQUIST, Carmen S.; COELHO, Clair C; SOUZA LAGO, Mara C.; LISBOA, Teresa K. (Orgs.). Leituras de Resistência: corpo, violência e poder. Florianópolis: Mulheres, v. 2, p. 81-103, 2009.

et al. A educação 'da família' como estratégia governamental de inclusão social: um estudo situado na interface dos estudos culturais, de gênero e de vulnerabilidade. Porto Alegre/RS: UFRGS/CNPq (Relatório de pesquisa). Faculdade de Educação, Universidade Federal do Rio Grande do Sul, Porto Alegre: 2008.

Gênero e educação: teoria e política. In: LOURO, Guacira L.; NECKEL, Jane F.; GOELLNER, Silvana (Orgs.). Corpo, gênero e sexualidade: um debate contemporâneo na educação. Petrópolis: Vozes, 2011. v. 1, p. 9-27.

PARAISO, Marluce, Raciocínios generificados no currículo escolar e possibilidades de aprender. In: LEITE, Carlinda et al. (Orgs.). Políticas, fundamentos e práticas do currículo. Porto: Porto Editora, 2011. v. 1, p. 147-160.

RIO GRANDE DO SUL. Secretaria da Saúde. Programa Primeira Infância Melhor. Guia da família. 7. ed. Porto Alegre: Companhia Rio-Grandense de Artes Gráficas (CORAG), 2016. 96p.

. Secretaria da Saúde do Estado do Rio Grande do Sul. Programa Primeira Infância Melhor. Guia de Orientação para GTM, Monitor e Visitador. Contribuições para políticas na área do desenvolvimento infantil. Porto Alegre: Relâmpago, 2007. 70p.

Secretaria Estadual de Saúde. Primeira Infância Melhor. O que é. Disponível em: 〈http://www.pim. saude.rs.gov.br/v2/opim/o-que-e/>. Acesso em: 20 mar. 18.

SCOTT, Joan. Fantasy E. História e a construção da identidade. Labrys, Estudos Feministas. n. 1-2, jul/dez. 2002. Disponível em: www.unb.br/ih/his/gefem/labrys1 2/scott1.html> Acesso em: 06 abr. 2006.

Gênero: uma categoria útil de análise histórica. Educação \& Realidade. Porto Alegre: v. 20, n 2, p. 71-99, 1995.

SHORE, Cris; WRIGHT, Susan. Antropology of policy: critical perspectives on governance and power. London: Routledge, 1997.

VICTORA, Ceres Gomes et al. Pesquisa qualitativa em saúde: uma introdução ao tema. POA: Tomo Editorial, 2000. 


\section{RESUMO}

Este trabalho analisa uma política pública, voltada para a promoção de uma Primeira Infância Melhor (PIM), compreendendo-a como uma instância pedagógica que se propõe a educar mulheres, no sentido de instituir formas de exercer a maternidade. A pesquisa inscreve-se nos campos dos estudos de gênero e dos estudos foucaultianos, e o material empírico, examinado na perspectiva da análise de discurso, foi produzido em um trabalho de campo de caráter etnográfico, realizado no município de Canoas (RS). Interessa-nos indicar a articulação que se faz entre determinadas formas de exercício da maternidade, vulnerabilidade social e políticas públicas, pois é nessa conexão que as mulheres são posicionadas como agentes centrais e chamadas a se responsabilizar, por meio do exercício/delimitação de funções maternas, pela promoção de ações em torno do desenvolvimento integral das crianças.

Palavras-chave: Educação. Maternidade. Políticas Públicas.

\section{PEDAGOGIES OF MOTHERHOOD IN THE BETTER EARLY CHILDHOOD POLICY /RS}

\section{ABSTRACT}

This paper analyzes a public policy, known as Better Early Childhood (PIM), by understanding it as a pedagogical action intended to educate women in the sense instituting ways of experiencing motherhood. The research is grounded on the fields of gender studies and Foucauldian studies; the empirical material, examined from the perspective of discourse analysis, was produced through an ethnographic field work in the city of Canoas (RS). We are interested in pointing out the articulation between certain ways of experiencing motherhood, social vulnerability and public policies, since it is in such connection that women are positioned as central agents and called to be responsible for actions aimed at the whole development of children, by means of exercise/delimitation of maternal functions.

Keywords: Education. Motherhood. Public Policies.

\section{PEDAGOGÍAS SOBRE MATERNIDAD EN EL ÁMBITO DE LA POLÍTICA PRIMERA INFANCIA MEJOR/RS}

\section{RESUMEN}

Este trabajo analiza una política pública, orientada a la promoción de una primera infancia mejor (PIM), comprendiendo a ésta como una instancia pedagógica que se propone educar a mujeres, en el sentido de instituir formas de ejercer la maternidad. La investigación se inscribe en los campos de estudios de género y de los estudios foucaultianos, y el material empírico, examinado desde la perspectiva del análisis de discurso, producido en un trabajo de campo de carácter etnográfico, realizado en el municipio de Canoas (RS). Nos interesa indicar la articulación que se hace entre determinadas formas de ejercicio de la maternidad, vulnerabilidad social y políticas públicas, porque es en esa conexión que las mujeres son posicionadas como agentes centrales y llamadas a responsabilizarse, por medio del ejercicio / delimitación de funciones maternas, en base a la promoción de acciones para el desarrollo integral de los niños.

Palabras-clave: Educación. Maternidad. Políticas Públicas. 